Linguistik Terapan 15 (1) (2018): 15-25

Jurnal Linguistik Terapan Pascasarjana

Available online http://jurnal.unimed.ac.id/2018/index.php/JLT-

$\underline{\text { Unimed }}$

\title{
COHORT-BASED GRAMMAR TEACHING MODEL DEVELOPMENT IN STRUCTURE SECTION OF TOEFL AT SEKOLAH TINGGI ILMU MANAJEMEN SUKMA MEDAN
}

\author{
Hidayat \\ Busmin Gurning \\ Rahmad Husein
}

Diterima Januari 2018; Disetujui Pebruari 2018; Dipublikasikan April 2018

ABSTRACT

This research makes use of Research and Development method in which a teaching model is developed to teaching grammar in the form of multiple-choice questions. It is Cohort-based Grammar Teaching Model that is developed. In the development of this teaching model, fifty students took part in. The research was conducted at Sekolah Tinggi Ilmu Manajemen Sukma Medan on jalan Sakti Lubis no. 80. To figure out what teaching model which the students need, questionaire was disseminated. In analyzing the available data from the instrument, questionaire inspired by Guttman Scale was made with numerous modifications in statements and questions. The analysis reveals that the participants require an intersting and fun grammar teaching model; easy to understand and more efective; quick problem-solving, time-saving and target-oriented. Due to this reason, eventually, Cohort-based Grammar Teaching Model is not mediocrewhere it is capable of alternating grammar problem for multiple-choice question in structure part of the TOEFL in a relative instant high result way.

Keywords: Research and Development, Teaching Grammar, Multiple-choice question, Cohort

How to Cite: Hidayat (2018). Cohort-Based Grammar Teaching Model Development In Structure Section Of Toefl At Sekolah Tinggi Ilmu Manajemen Sukma Medan. Jurnal Linguistik Terapan Pascasarjana Unimed, 15 (1): 15-25

ISSN 2407-7410

\section{INTRODUCTION}

Most teachers consider teaching grammar at school has something in common as in teaching structure and written expression in TOEFL. However, it does not. Teaching grammar at school orients at the understanding and assessment of the students. Teaching TOEFL professionally only needs a couple of weeks, approximately 12-15 meetings to enhance and to gain top score. To gain success in 
grammar in structure section of TOEFL, the teaching model should be amended. There are numerous sub-topics in structure and written expression requiring fast alternative in which insisting teachers to rack their brains to figure out what it is. What should be kept in mind is that the test takes are timed. So, while teaching, teachers should consider an effective way to be demonstrated before performing right in front of the class, unless it becomes wasting time.

Based on the observation, every teacher claims that he/she has his/her own way of teaching. Based upon the fact, it does not assist much. This reveals that this wound and pain need a special remedy to be cured. Sometimes teachers are discussing each question deeply rather than identifying each answer. In addition, they never connect it with the four options with the questions. Teachers if to be considered as professional with their persistent teaching model will identify the problem in the question by only glaring at the four choices, not from the question.

To overcome this problem, a fast and effective one is in need. It is believed that there is a massive enquiry of the existence of a new model of teaching as the number of English learners who intend to grab sandwich program and scholarship becomes greater this day and in the future. Due to this reason, cohort model is the resolution. The same cohort model application has been used by Dalla Bella et al (2005) to identify and determine melody in songs. This model was developed as alternative one where other models got failure in melody identification. Cohort Model could give significant contribution to English learners who flopped to gain the expectation this day. Teaching grammar in structure section of TOEFL with cohort model will answer the question by offering two solutions, professionalism in teaching for teachers and easiness for English learners. Firstly, this teaching model will show English teachers how to get accustomed to how to explain and to entertain the English learners with the questions and the options. Thus, well-trained English teacher will provide interesting explanation on each sub-topic although the questions are complicated. Finally, if this application of is applied over times, masters of grammar in structure section of TOEFL will exist. Secondly, English students will focus on each question, answer the questions easily, avoid confusion, save time for every single question, and obtain high score in a relatively short time of learning as expected. Thus, the researcher intends to know the structure of teaching model exists at STIM Sukma Medan; the students' need in learning English structure; and the theoretical model of teaching structure based upon cohort model developed.

\section{REVIEW OF RELATED LITERATURE}

\section{William Marslen-Wilson's Cohort Model}

To understand spoken language is to relate sound to meaning. At the core of this process is the recognition of spoken words, since it is the knowledge representations in the mental lexicon that provide the actual bridge between sounds and meanings, linking the phonological properties of specific word forms to their syntactic and semantic attributes. This duality of lexical representation enables the word-recognition process to mediate between two radically distinct computational 
domains the acoustic-phonetic analysis of the incoming speech signal, and the syntactic and semantic interpretation of the message being communicated.

The overall process of spoken word-recognition breaks down into three fundamental functions. They refer to as the access, the selection, and the integration functions. The first of these, the access function, concerns the relationship of the recognition process to the sensory input. The system must provide the basis for a mapping of the speech signal onto the representations of wordforms in the mental lexicon. Assuming some sort of acoustic-phonetic analysis of the speech input, it is a representation of the input in these terms that is projected onto the mental lexicon.

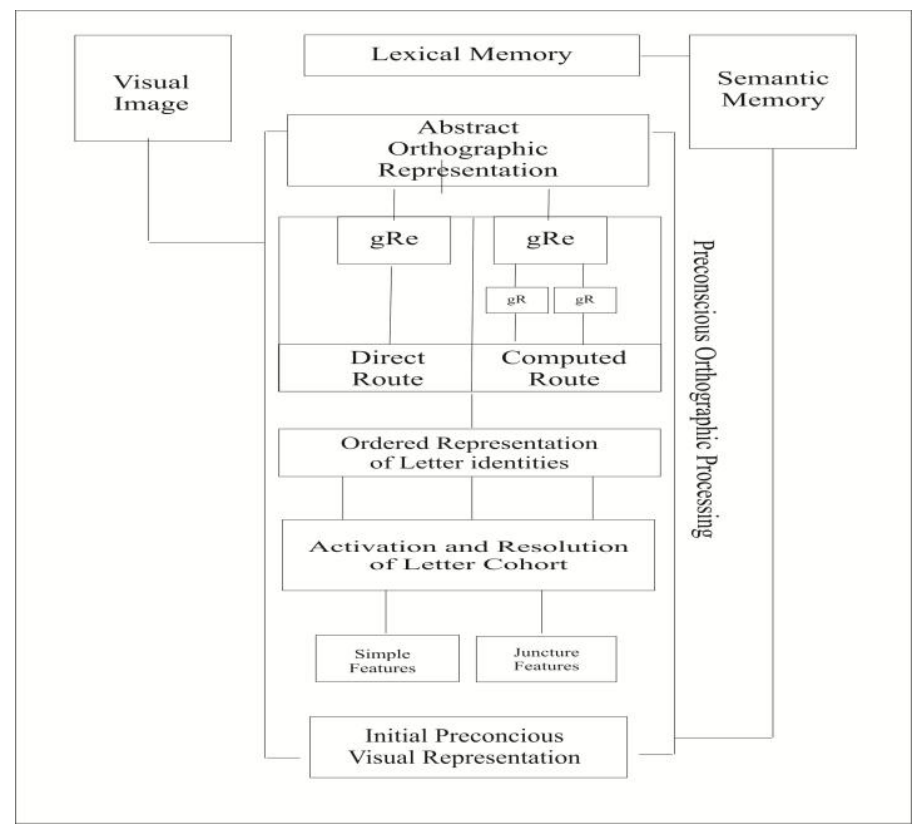

Figure 2.4 Marslen-Wilson's Cohort ModelSample experiment
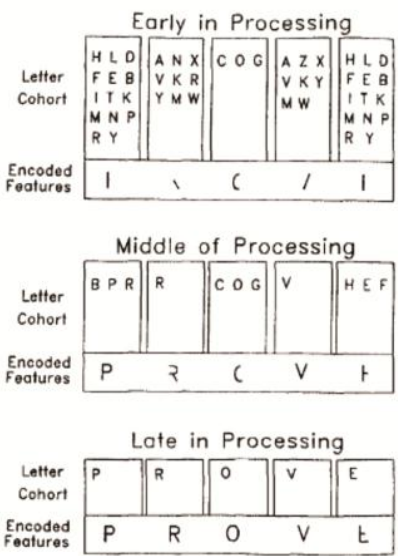

When the first feature for a letter position is encoded it activates, as letter cansudates for that position. all letters with which it is consistent, As adcitional features ate not consistent, and the cobort is resolved (i.e., the letter for that position is identified) when only a single candidate remains

Figure 2.5 Cohort Experiment 


\section{The Earliness of Spoken Word Recognition}

The crucial constraint on the functional properties of access and selection is the earliness of correct selection. This is to be defined as the reliable identification of spoken words, in utterance contexts, before sufficient acoustic-phonetic information has become available to allow correct identification on that basis alone. If this can be demonstrated, then it places strong restrictions not only on how the selection process is organized, but also on the ways in which representations are initially accessed from the bottom-up.

To prove early selection, two things must be established. The first is how long it takes to recognize a given word. This reflects the timing with which the selection function is completed. The second is whether the acoustic-phonetic information available at this estimated selection-point is or is not sufficient, by itself, to support correct identification.

The major techniques for establishing the timing of on-line word-recognition- thereby answering the first of these two questions-involve fast reaction- time tasks. Typical examples are the shadowing and the identical monitoring tasks, where the listener responds directly to the words he hears either by repeating them aloud, or by making a detection response to a word-target. The mean reaction-times in such tasks, measured from word onset, can be used as a direct estimate of selectiontime, subject to a correction factor to allow for the time it takes to execute the response.' Typical values obtained in these tasks (for one- and two-syllable content words heard in normal utterance contexts) are of the order of 250-275 ms, which, with a correction factor of 50-75 ms, gives a mean selection-time of around 200 ms (e.g., Marslen-Wilson, 1973, 1985; Marslen-Wilson \& Tyler, 1975, 1980).

Similar values can be obtained, more indirectly, from reaction-time tasks where the listeners are asked to respond, not to the word itself, but to some property of the word whose accessibility for response depends on first identifying the word in question. Examples of this are the rhyme-monitoring results reported by Marslen-Wilson \& Tyler $(1975,1980)$ and others (e.g., Seidenberg \& Tanenhaus, 1979), and at least some research involving the phoneme-monitoring task (e.g., Marslen-Wilson, 1984; Morton \& Long, 1976). By subtracting an additional constant from the response-times in these tasks, to take into account the extra phonological matching processes they involve, one again arrives at selection-times for words in context of the order of $200 \mathrm{~ms}$ from word-onset.

But these estimates are only half of the equation. It is also necessary to establish whether or not the acoustic-phonetic information available at these selection-points is sufficient for correct selection. For the research described above, this could only be done indirectly, by estimating the average number of phonemes that could be identified within $200 \mathrm{~ms}$ of word-onset, and then using that estimate to determine how many words would normally still be consistent with the input. If, as the available measurements suggest, $200 \mathrm{~ms}$ would only be enough to specify an initial two phonemes, then there would on average be more than 40 words still compatible with the available input (this estimate is based on the analysis of a 20,000-word phonetic dictionary of American 
English (Marslen-Wilson, 1984)). The limitation of this indirect inference to early selection is that it cannot take into account possible coarticulatory and prosodic effects. This could lead to an underestimate of the amount of sensory information actually available to the listener after $200 \mathrm{~ms}$.

The second main technique allows a more direct measure of the sufficiency of the acousticphonetic input available at the estimated selection-point. This is the gating task, as developed by Grosjean (1980), and exploited by Tyler and others (e.g., Salasoo \& Pisoni, 1985; Tyler \& Wessels, 1983). Listeners are presented with successively longer fragments of a word, at increments ranging (in different experiments) from 20 to $50 \mathrm{~ms}$, and at each increment they are asked to say what they think the word is, or is going to become. This tells us exactly how much acoustic-phonetic input the listener needs to hear to be able to reliably identify a word under various conditions. In the original study by Grosjean (1980), we find that subjects needed to hear an average of $199 \mathrm{~ms}$ of a word when it occurred in sentential context, as opposed to $333 \mathrm{~ms}$ for the same acoustic token presented in isolation.

Because of the unusual way the auditory input is presented in the gating task, there has been some criticism of its validity as a reflection of normal word-recognition processes. Since the listener hears the same fragments repeated many times in sequence, this might encourage abnormal response strategies. This objection is met by Cotton and Grosjean (1984) and Salasoo and Pisoni (1985), whose subjects heard only one fragment for any given word, and where the pattern of responses matched very closely the results for the same words when presented as complete sequences to each subject.

It is also possible that responses are distorted by the effectively unlimited time-in comparison to normal listening-that listeners have available to think about what the word could be at each presentation. This objection is met by Tyler and Wessels (1985), in an experiment where subjects also heard only one fragment from each word, and where they responded by naming the word as quickly as possible. Mean naming latencies were $478 \mathrm{~ms}$ from fragment offset, and the response patterns again closely corresponded to those obtained without time-pressure.

In a recent study (Brown, Marslen-Wilson, \& Tyler, unpublished) we have combined reaction-time measures for words heard normally with gating tests for the same words. This provides the most direct evidence presently available for early selection. In the first half of the experiment, subjects monitored pairs of sentences for word targets, with a mean reaction-time for words in normal contests of $241 \mathrm{~ms}$. This gives an estimated selection-time of $200 \mathrm{~ms}$ or less. In the second part of the experiment, the target-words were edited out of the stimulus tapes and presented, as isolated words, to a different set of subjects in a standard gating task. The mean identification-time estimated here was $301 \mathrm{~ms}$, indicating that the words were being responded to in the monitoring task some $100 \mathrm{~ms}$ before sufficient acoustic-phonetic information could have accumulated to allow recognition on that basis alone.

Given, then, that we have accurate and reliable estimates of the two variables in our equation, simple arithmetic tells us that content words, heard in utterance contexts, can usually be selected-and, 
indeed, recognized-earlier than would be possible if just the acoustic-phonetic input was being taken into account. Naturally, as Grosjean and Gee (1987, this issue) point out, some words-especially function words and short, infrequent content words-will often not be recognized early. In fact, under certain conditions of temporary ambiguity, as Grosjean (1985) has documented, "late" selection will occur, where the word is not only unrecognized early, but may not even be identified until the word following it has been heard. These observations nonetheless do not change the significance of the fact that a large proportion of words are selected early. A theory of lexical access has to be able to explain this, just as it has to deal with late selection as well. Late selection, however, places far weaker constraints on the properties of the recognition process than does early selection.

A different type of objection is methodological in character. It is argued that none of the tasks used to establish early selection are measuring "real" word-recognition. Instead, by forcing subjects to respond unnaturally early, they elicit some form of sophisticated guessing behavior. Forster (1981), for example, argues that when a subject responds before the end of the word, as in the shadowing task, he must in some way be guessing what the word will be, on the basis of fragmentary bottom-up cues plus knowledge of context.

Such objections, however, have little force. First, because the claim that subjects are responding "unnaturally early" does not have any independent empirical basis. There is no counter evidence, from "more natural" tasks, showing that under these conditions different estimates of recognition-time are obtained-nor is the notion "more natural task" itself easy to defend except in terms of subjective preference. Secondly, to distinguish under these conditions between "perception of the target word and guessing" (Forster, 1981, p. 490; emphases in original) is to assume, as a theoretical a priori, a particular answer to the fundamental questions at issue.

Forster apparently wants to rule out, as an instance of normal perception, cases where the listener responds before all of the sensory information potentially relevant to that response has become available. But this presupposes a theory of perception where there is a very straightforward dependency between the sensory input and the corresponding percept. The claims that have been trying to develop here allow for the possibility of a less direct causal relationship between the sensory input and the percept (see Marcel, 1983, for a discussion of some related issues). These claims may or may not prove to be correct. But one cannot settle the issue in advance by excluding evidence on the grounds that it conflicts with the theoretical assumptions whose validity one is trying to establish. If one is advancing the view that normal perception is just the outcome of the integration of partial bottom-up cues with contextual constraints, then it is not an argument against this view simply to assert that perception under these conditions is not perception.

\section{RESEARCH METHOD}

This study was conducted by using Research and Development which mechanisms based upon Borg and Gall (2003). Data in this study covers the students and the teacher. The number of the student is 
52 people from semester IV and semester VI, and there is one teacher. Students filled out the questionnaire provided by researcher and the teacher was interviewed directly. There are three kinds of data collection: they are questionnaires and documents.

\section{FINDINGS AND DISCUSSION}

\section{The Analysis of Students' Need}

From the questionnaire, the analysis in which the data derived can be described as follow.

Table 4.1. Analysis of Explicit Grammar Teaching Model

\begin{tabular}{|c|l|c|c|}
\hline No & \multicolumn{1}{|c|}{ Analysis of the Existing Teaching Model } & \multicolumn{2}{|c|}{ Percentage \% } \\
\cline { 3 - 4 } & & YES & NO \\
\hline 1 & To understand English grammar is complicated & 86,5 & 13,5 \\
2 & The Explicit Grammar Teaching Model is boring & 96,15 & 3,85 \\
3 & The grammar question in structure section of TOEFL & 86,5 & 13,5 \\
& is difficult. & & \\
\hline
\end{tabular}

From the the data displayed in the table above, teaching grammar using Explicit Grammar

Teaching Model is difficult to understand. The table above indicates that 45 participants $(86,5 \%)$ out of 52 agree with that statement. As the statement goes on, in addition, it is found that the existing teaching model used by teacher is boring for the students to grab English grammar. It can be seen from the table that $96,15 \%$ (50 students) of the participants stated so. This condition was getting deteriorate when the students was provided grammar question, to see their ability in grammar mastery. It reveals that most of them find the grammar question in structure section of TOEFL is hard to complete. There were 45 participants (86\%) who were not capable of doing the question well.

The students' need analysis result is also in line with the result of the teacher's interview. Rules and vocabularies are taught. The major focus of the teacher is teaching rules. However, the teacher is not sure if they understand it or not, confused or well-accepted. The rules and vocabularies covers the teaching verbs, noun, adverb, clauses, conjunction, participle etc to students. The table beneath illustrates the teaching grammar based on explicit grammar teaching model.

Table 4.2. Result of Teacher Interview

\begin{tabular}{|l|c|c|}
\hline \multicolumn{1}{|c|}{ Subject } & Yes & No \\
\hline Teaching rules & $\sqrt{ }$ & \\
Teaching vocabularies & $\sqrt{ }$ & \\
Tense & $\sqrt{ }$ & \\
\cline { 1 - 2 } & & \\
\cline { 1 - 2 } Grammar mastery Output & & $\sqrt{ }$ \\
Speaking proficiency & & $\sqrt{ }$ \\
Writing & & $\sqrt{ }$ \\
\hline
\end{tabular}

\section{The existing teaching model}

The students' need analysis and the interview result from the lecture indicate that the existing teaching model serves grammar dominantly. The rules and vocabulary mastery in its teaching process 
make students difficult to understand. In teaching and learning English teaching model in which emphasizes the teaching of rules and vocabulary mastery is Explicit Grammar Teaching Model. The process of mastery rules and vocabularies in grammar is complicated according to students. Therefore, it leads to boredom. It becomes deteriorated when it does not assist students' problem in overcoming grammar question in structure section of TOEFL. In other word the teaching of rules and grammar using this model fails as it does not answer students need in the present time.

\section{The students' need in learning English structure}

Unlike the table above, induction in Cohort-based grammar teaching model results in outstanding output. From the analysis, it reveals that the new teaching model, Cohort-based grammar teaching model provides easiness. It can be seen from the number of participants who agree with it (94,23\%). Cohort-based grammar teaching model is not only easy to grab but also interesting and fun to do $(76,92 \%)$. In addition, by using Cohort-based grammar teaching model in completing structure part of TOEFL can save times as it is capable of finishing the question more easily. The following table is the result of the analysis of Cohort-based grammar teaching model uses in tackling grammar question in TOEFL.

Table 4.3. Result of Cohort-based Grammar Teaching Model Analysis

\begin{tabular}{|c|l|c|c|}
\hline No & Analysis of Cohort-based Grammar Teaching Model & \multicolumn{2}{|c|}{ Percentage \% } \\
\cline { 3 - 4 } & & YES & NO \\
\hline 1 & To understand English grammar is not difficult. & 94,23 & 5,77 \\
2 & The Cohort-based Grammar Teaching Model is & 76,92 & 23,08 \\
3 & interesting and fun. & 86,53 & 13,47 \\
& Using Cohort-based Grammar Teaching Model, the & & \\
& grammar question in structure section of TOEFL can & & \\
be solved easily. & & \\
\hline
\end{tabular}

\section{The theoretical model of teaching structure based upon cohort model developed}

Cohort model of speech recognition covers three elements in its mechanism in recognizing speech. The elements are recognition, semantic code activation and selection. In the developing grammar teaching based on Cohort Model there are only two elements will be used. Recognition and selection are two crucial elements in the development of this teaching model.

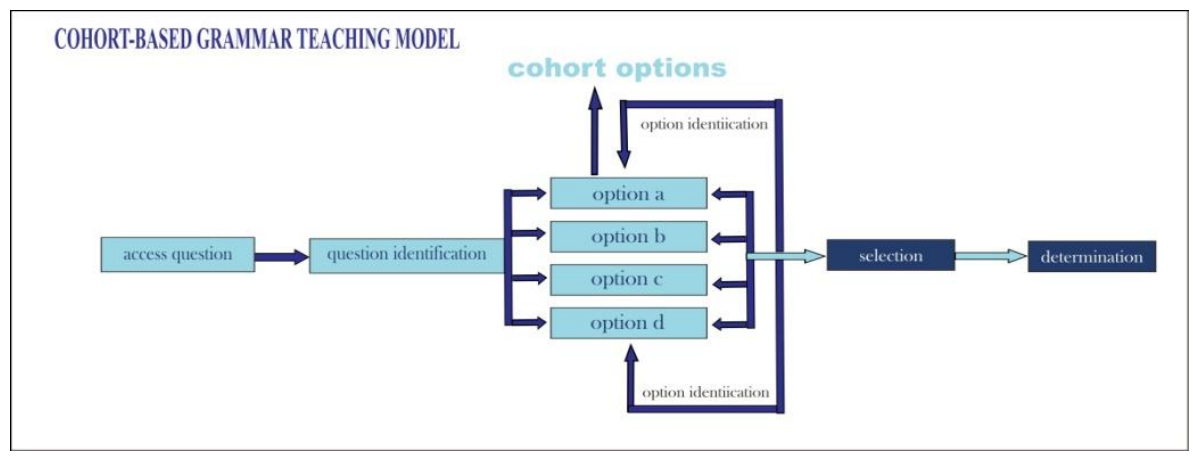

Illustration 4.1 Cohort-based Grammar Teaching Model 
The development of recognition in grammar teaching is a process of recognizing or identifying two important parts of the grammar question, the question itself and the options. The grammar question targeted based on this model must be in the form of multiple- choice. The recognition of the question aims at identifying grammar problem occurred in the question itself, and the recognition process of the options is to convince if the first identification in the question matches the identification of the options. When matching process of the two identifications complete, the process of selection begins. The selection starts to eliminate one option or two. The selection process bails out the student to narrow down the options. If the recognition of question and options and the selection of the options well employed, the narrowing down process will then find one precise answer. To do it well, all is written in rules and restrictions.

\section{a. Access}

Access in cohort model is the input of speech production to be recognized in the initial phase. There will be a couple of words called active cohorts. In the structure section in TOEFL the active cohorts are considered to be the four options of each question. When looking at the four of the options, the process of identification is running through each available question at almost the same time. The process of identification occurs both in given question and options. In question and options identification, students are taught to recognize problem rather than to discuss the grammar. Look at the access question and options below.

on the corner of the local bank ran away with

millions dollar of the bank customer some days ago.
A). The man
B). The man is standing
C). Standing
D). Is standing

What is the problem in the question? To answer it, there are two ways. First, what is needed, and another is what is not. The above question does not available, so what is needed is a subject. If students are not capable of recognizing the subject, other identification in the question must be done. The present of the verb in the access question is the second solution. There is a verb, ran away with. The upcoming steps will focus totally in the option in selection process.

\section{b. Selection}

In identifying each problem of each question, selection process could go through two phases. In phase I, the early selection normally involves the elimination of one or two options out of four. 
When the early selection could eliminate three options out of four, the process of other phase will come to a halt since the best answer is revealed. As the story goes on from the access question, the selection process runs this way

on the corner of the local bank ran away with millions dollar of the bank customer some days ago.
A). The man
B). The man is standing
C). Standing
D). Is standing

Subject is needed
A). The man

B). The man is standing

No verb and participle needed
A). The man

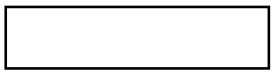

Because the question does not have subject, students must find only subject in the option. This can be conducted by deleting option (s) with (option C and D do not have subject) or verb (option B) because it requires only subject. automatically, the rest answer is option A. it is the best answer. As the answer found, students only went through phase I.

\section{CONCLUSIONS}

The result of data analysis in this study reveals findings as under:

1. The teaching of English in which grammar becomes the major focus does not grant students' improvement and understanding it well. Utilyzing explicit grammar teaching model in teaching rules and vocabularies is hard to be accepted by the students $(86,5 \%)$. Due to the reason, the students fell bored $(96,15 \%)$.

2. Based on the above condition, however, other grammar teaching model is required to terminate the boredom. Cohort-based grammar teaching is the solution to cover the previous grammar teaching model weakness, explicit grammar teaching model. Cohort-based grammar teaching model is interesting and fun $(76,92 \%)$ as it provides easy way $(86,53 \%)$ for the student in each difficult question.

\section{REFERENCES}

Grosjean, F. (1980). Spoken Word Recognition Processes and the Gating Paradigm. Perception \& Psychophysics, 28, 267-283

Halpern, A. R. (1984a). Organization in Memory for Familiar Songs. Journal of Experimental Psychology: Learning, Memory, and Cognition, 10(3), 496-512.

Halpern, A. R. (1984b). Perception of Structure in Novel Music. Memory \& Cognition, 12, 163-170. 
Ling, Zheng. (2015). Explicit Grammar and Implicit Grammar Teaching for English Major students in University. Changcun University, Vol. 12, 556-560.

Marslen-Wilson, W. D. (1987). Functional Parallelism in Spoken Word Recognition. Cognition, 25, 71-102.

Marslen-Wilson, W.D. (1984). Function and Process in Spoken Word Recognition - A Tutorial Review. In H. Bouma, \& D.G. Bouwhuis (Eds.), Attention \& Performance X. London: Lawrence Erlbaum.

Marslen-Wilson, W.D., \& Tyler, L.K. (1980). The Temporal Structure of Spoken Language Understanding. Cognition, 8, 1-71.

Marslen-Wilson, W.D., \& Welsh, A. (1978). Processing Interactions and Lexical Access During Word-Recognition in Continuous Speech. Cognitive Psychology, IO, 29-63.

Taft, M. (1979). Recognition of Affixed Words and the Word Frequency Effect. Memory \& Cognition, 7,263-272.

Tyler, L.K. (1984). The Structure of the Initial Cohort: Evidence from gating. Perception \& Psychophysics, 36, 417427.

Tyler, L.K., \& Wessels, J. (1983). Quantifying Contextual Contributions to Word Recognition Processes. Perception \& Psychophysics, 34, 409-420. 